
UNIVERSITY OF CALIFORNIA

\title{
APPLIED SCIENCE \\ DIVISION
}

THE DEPENDENCE OF INDOOR-DOLLUTANT CONCENTRATIONS ON SOURCES, VENTILATION RATES, AND OTHER REMOVAL FACTORS

A.V. Nero, Jr. and D.T. Grimsrud

August 1983

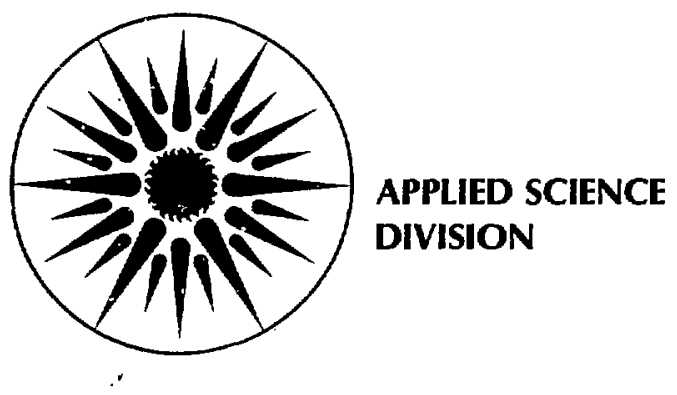


This report was done with support from the Department of Energy. Any conclusions or opinions expressed in this report represent solely those of the author(s) and not necessarily those of The Regents of the University of California, the Lawrence Berkeley Laboratory or the Deparment of Energy.

Reference to a company or product name does not imply approval of recommendation of the product by the University of California or the U.S. Department of Energy to the exclusion of athers that may be suitable. 


\title{
THE DEPENDENCE OF INDOOR-POLLUTANT CONCENTRATIONS
}

ON SOURCES, VENTILATION RATES, AND OTHER REMOVAL FACTORS

\author{
Statement before a joint hearing of the \\ Energy Development and Applications \\ and Natural Resources, Agriculture \\ Research and Environment Subcommittees of the \\ House Committee on Science and Technology \\ Anthony V. Nero, Jr. \\ (w1th Dayld T. Grimsrud as co-author) \\ Buflding Ventilation and Indoor A1r Quallty Project \\ Applied Science Division \\ Lawrence Berkeley Laboratory \\ University of California \\ Berkeley, CA 94720
}

August 2, 1983

\section{DISCLAIMER}

\begin{abstract}
This report was prepared as an account of work sponsored by an agency of the United States Government. Neither the United States Government nor any agency thereof, nor any of their employees, makes any warranty, express or implied, or assumes any legal liability or responsibility for the accuracy, completeness, or usefulness of any information, apparatus, product, or process disclosed, or represents that its use would not infringe privately owned rights. Keference herein to any spe:ific commercial product, process, or service by trade name, trademark, manufacturer, or otherwise does not necessarily constitute or imply its endorsement, recommendation, or fayoring by the United States Government or any agency thereof. The views and opinions of authors expressed bercin do not necessarily state or reflect those of the United States Government or any agency thereof.
\end{abstract}

This work was supported by the Assistant Secretary of Renewable Energy, Office of Bullding Energy Research Bullding Systems Division and the Director, office of Conservation and and Development, Human Health and Assessments DIvision and Pollutant Characterization and Safety Research DIvision of the U.S. Department of Energy under Contract No. DE-ACO3-76SF00098.

\section{AOTIBE}

POATIONS OF THIS REPORT ARE ILLEIBLE.

It has been reproduced from the best available copy 20 permit the broadest 


\section{Table of Contents}

Introduction

Characterization of Pollutant Behayior:

A Principal Element in Indoor Air Quallty Research

Indoor Air Quality Studies at the Lawrence Berkeley Laboratory

Particulates, Radon Daughters, and their Control

Indoor Air Quality Research Needs and Cooperation Requirements

References

Attachment 1:

A National Survey of Indoor Afr Quality

Attachment 2:

Federal Research Needs on Indoor Alr

Quality and Energy Conservation 
We appreciate the invitation to review with you the question of indoor air quality: what has been done to this date, what the current state of understanding $1 \mathrm{~s}$, and what needs to be done in the foreseeable future, all to elucidate the degree of human exposures to indoor airborne pollutants, the factors affecting those exposures, their effects on human health, and what may be done to assure adequate indoor air quality. Our current underscanding is now sufficient to state that indoor concentrations of important airborne pollutants of ten exceed outdoor levels, an ironic state of affairs considering the substantial efforts that have been devoted to characterizing and controlling outdoor pollutant levels, and the fact that the population actually spends most of its time indoors. For pollutants where such comparisons are possible, indoor concentrations of ten exceed outdoor a1r quality standards, sometimes by large factors, and -- for some pollutants -- indoor concentrations even appear to exceed occupational standards in a significant portion of the bullding stock. Hence the interest in devoting substantial efforts to this problem, including the aspect that I will emphasize, 1.e., the characterization of indoor pollutant behavior.

In addressing this question $I$ will include the behavior of several classes of chemical and physical pollutants: emissious from combustion appliances; radon and its progeny; and formaldehyde and other organics. I will not review various living organisms present in indoor afr, or even special chemical and physical materials that are sometimes present. As you will see, this question of the dependence of Indoor pollutant concentrations on sources, ventilation rates, and other removal mechanisms, for which I use the expression "indoor pollutant behavior," is closely tied to understanding how energy conservation is related to indoor air quality.

In what follows, I will

1) Indicate briefly the role of research on indoor pollutant behavior in the context of overall research on indoor a1r quality;

2) summarize key aspects of the work of our group at Lawreace Berkeley Laboratory (LBL), ons

Cindoor air quality, emphasizing questions of pollutant behavior and pointing out the most important research needs in these areas;

3) review specifically the current state of knowledge of particulates, radon progeny, and their control; and finally

4) summarize general research needs on the behavior of indoor pollutants, lndicating how this research ought to fit into the overall work to be performed on indoor alr quality.

Characterization of Pollutant Behavior: A Principai Element in Indoor Air Quality Research

Broadly speaking, the ultimate objectives of indoor air quality research are to determine tunan exposures by measurements of pollutant 
concentrations ("monitorlng"), to ascertain the effiects of these exposures on the health of the population ("health studies"), and to formulate strategies to limit exposures and associated haalth effects ("control strategles"). It 1s easy to leave out a fourth principal topic that is investigated to a greater extent in the laboratcry and which to a substantial degree underlies these three more apparent research areas, 1.e., pollutant characterization.

A satisfactory understanding of 1ndoor air quality clearly requires study of how pollutants behave indoors: the sources of pollutants, the effect of changes in ventilation rate on concentrations, and the manner in which pollutants are transformed or removed by interactions wtth each other or with the bullding and its contents. Moreover, study of these questions is clearly required to achieve the main objectives of indoor air quality research: monitoring cannot be perfurmed properly or interpreted adequately without laboratory studies of pollutant behavior and, conversely, the results of largescale monftoring sontribute directly to an understanding of the factors determining follutant concentrations in the actual building stock; health studies require adequate characterization of the pollutant mixtures to which humans are exposed, which are sumetimes even parameterized in terms of ine factors, such as sources and ventilation rates, which affect these concentrations and control strategies can only be chosen jith an understanding of the factors affecting pollutant concentrations and of the effectiveness of varfous techniques for reducing them.

The situation is entirely analogous to understanding important problems with the outdoor atmosphere, such as acid rain or $\mathrm{CO}_{2}$. For such questions, outdoor monitoring is only one component in a research strategy that must also contain experimental and theoretical studies, often iaboratory based, to elucidace the chemical and physical mechanisms at work and to provide a basis both for interpreting measurements performed in the atmosphere and for adopting control straregies. As you will see, much of the work of the grous at LBL is directed to analogous characterization studies that are fundamental to an understanding of indoor air quality.

Such studies are, of course, at the heart of understanding the relationship between energy conservation and indoor air quality. It is the bullding shell, its contents, and local physical and environmental factors that determine pollutant concentrations indoors. In general, these are the same factors that affect energy consumption in homes and other bulldings. Conversely, efforts to save energy can alter building-related factors, including not only ventilation rates, but also material and appliance source types and other factors affecting concentrations. Moreover, efforts to control indoor concentrations, whether increases due to energy-saving measures or concenrrations that were excessive in any case, require attention to such building-related factors.

Indoor A1r Quaiity Studies at the Lawrence Berkeley Laboratory

Work on Indoor air quality at LBL began with a study of einisstons from combustion appliances, following measurements in local 
"WHITE FLAME" CONVECTIVE HEATER
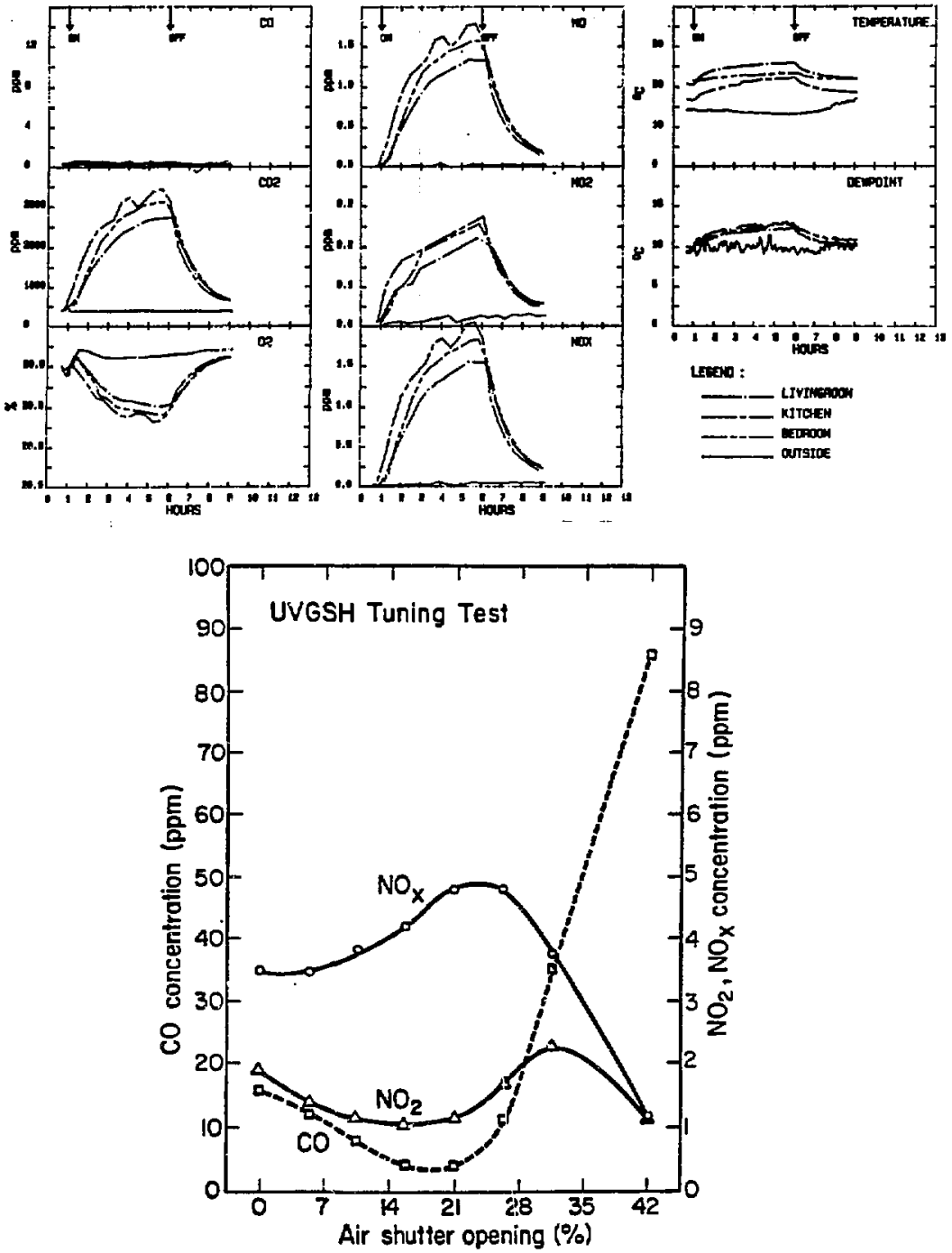

Figure 1 (top) Concentration profiles of emissions during operation of a portable kerosequ-fired space heater. The heater was located in the living room of a $240 \mathrm{~m}$ house with 0.55 a1r changes per hour. $\underline{F l g u r e} \underline{2}$ (bottom) Peak pollutant concentrations as a function of airshutter opening for an unvented gas-fired space heater. Measurements were made $1 \mathrm{n}$ a $27 \mathrm{~m}^{3}$ chamber with 0.4 air changes per hour. 
homes that showed that concentrations of key combustion products were often much higher Indoors than outdoors, although air quality standards presumed that outdoor levels were those of concern (Ref. 1). Beginnirg in 1976, the prograin expanded substantially, in order to ascertain the potential effects of energy conservation measures on indoor air quality and to understand how to avoid significant deterioration. This program has had diverse elements, many of which I will indicate briefly.

Before proceeding to the core of that work, most of which has been performed in the laboratory or in "research houses," I should mention that one of the major elements of this expanded program was a large moblle laboratory that traveled around the country to a variety of homes and other buildings, carrying with it instrumentation for monitoring a wide range of pollutants intensively over long periods of time (Ref. 2). The mobile lab effort gave a substantial amount of basic information on the occurrence of these pollutants indoors (e.g., Ref, 3). What it also indicated fairly clearly, consistent with our earlier work, was that the major question for indoor air quality was not the pollutants that entered from outdoor alr, but rather those released directly into bulldings from the materials or appliances that generated them. Although there are exceptions to this generalization, this meant that characterizing indoor alr quality was principally a question of the study of indoor-generated pollutancs. The major connection with outdoor air quality issues is that the vast attention paid to improving outdoor afr quality and controlling emissions into the general environment, while important, has tended to ignore the fact that most human exposures to air pollution may occur to the general population in their homes and non-industrial work places, where levels often far exceed outdoor levels and where people spend most of their time.

Our research has therefore tended to emphasize characterization of the dependence of indoor concentrations on sources, ventilation rates, and other factors that cause pollutant transformations or removal indoors.

combustion products: Our group has characterized emissions rates from gas stoves, kerosene heaters, and unvented gas-fired space heaters in an environmental chamber, and has also studied these devices (and wood stoves) in test houses. The objective has been to determine, not only thelr effect on indoor concentrations, but also the manner in which emlssions propagate through a structure under various ventilation conditions. The result of such work is the knowledge that some emisstons, such as oxides of nitrogen and carbon, can reach very high levels indoors. Wven so, it is clear that further work is required in characterizing emissions from combustion appliances, and in understanding their transport and transformation properties (e.g., NO/NO conversion) in indoor atmospheres. These issues are 1mportant, not only for understanding potential exposures and control measures, but also for characterizing the performance of monitoring instrumentation and the effectiveness of potential measurement strategies. (See Figs, 1-2 and Refs. 4-8)

$\underline{\text { radon and }}$ 1ts progeny: We have measured radon emission rates 

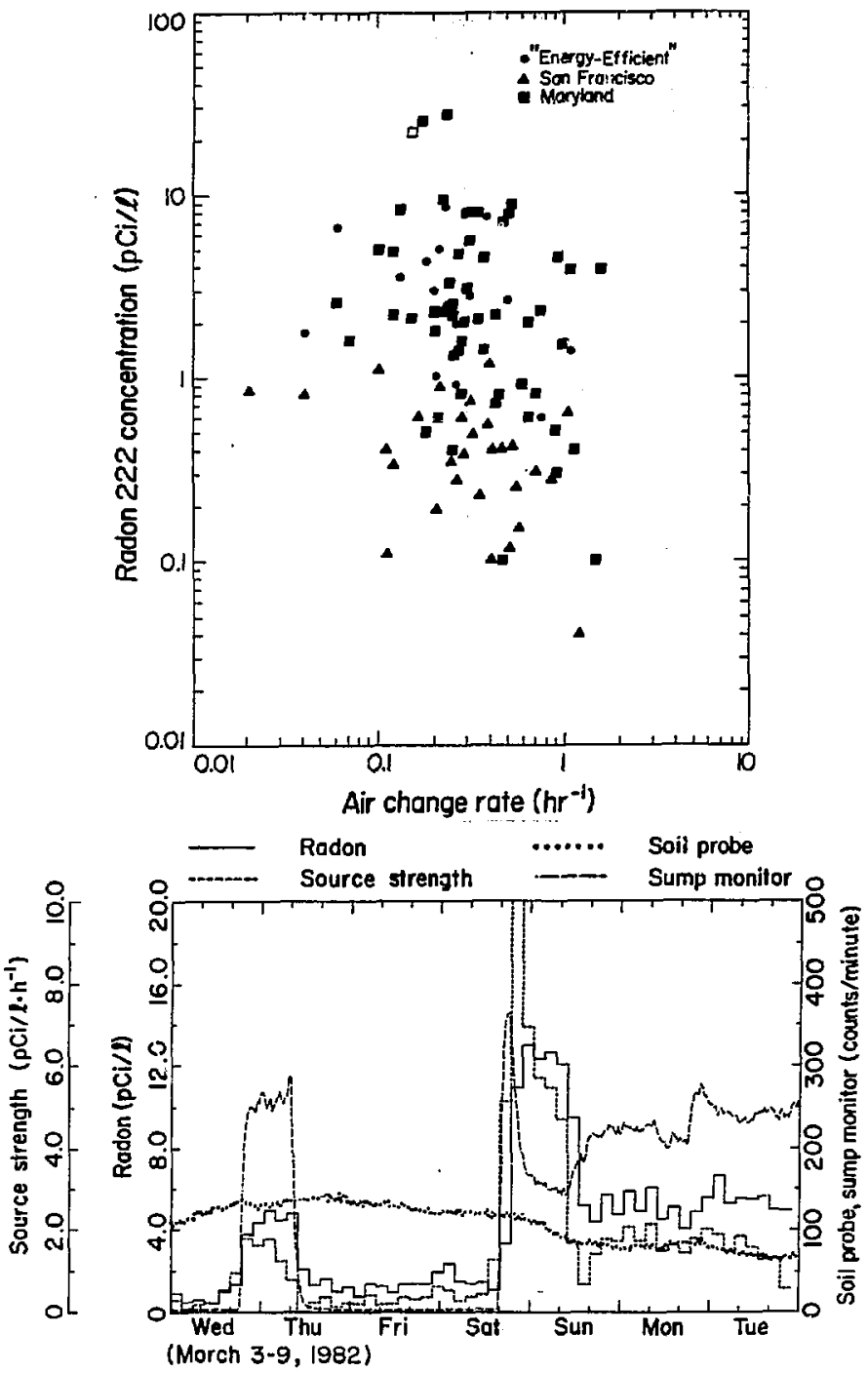

F1gure 3 (LOP) Measured radon concentrations and ventilation rates in energy-efficlent and conventional houses (about 100 houses total). E1gure 4 (bottom) Radon concentration, radon source strength (calculated from the radon concentration alr-exchange rates), alpha radioactivity in soll gas and in air above a basement sump pump. Data are from a singlefamily house near Chicago. 


\begin{tabular}{|c|c|}
\hline Condition & $\begin{array}{c}\text { Foranlde hyde } \\
\text { (ppb) }\end{array}$ \\
\hline Unoccupied, without furniture" & $67 \pm 97$ \\
\hline Unoceupled, vith furni ture" & $186 \pm 72$ \\
\hline Occupled, day" & $218 \pm 10 x$ \\
\hline Occupied, nightb & $117 \pm 312$ \\
\hline Outdoor ArE & $\langle 17$ \\
\hline
\end{tabular}

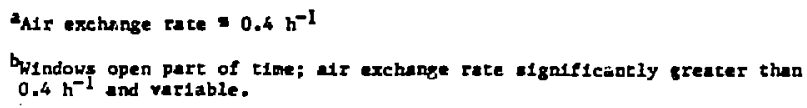

Comporison of Trace Organies in Indoor and Outdoor Air at on Otfice Site
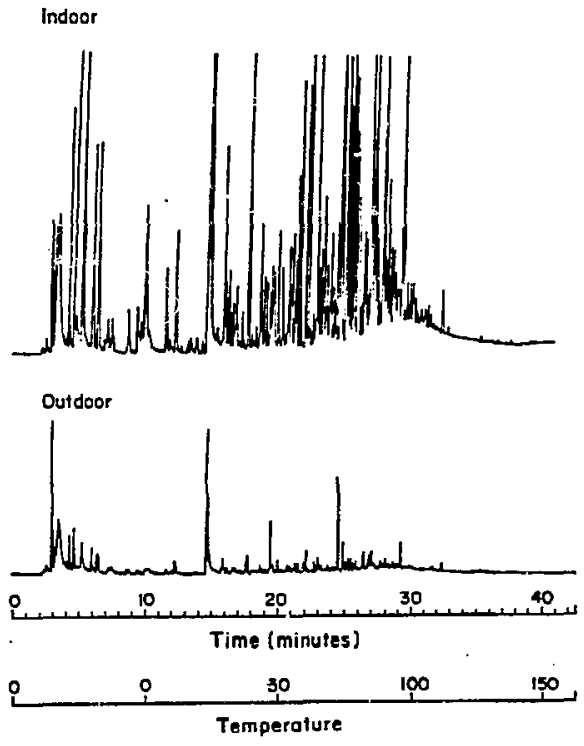

Eigure 5 Comparative gas chromatograms from iaside and outside an office where complaints had been registered regarding indoor air quality. Equal size air volumes were sampled using the Tenax-GC polymer. Individual peaks correspond to different chemlcal species or groups. 
from concrete samples collected around the country, and have performed concentration measurements and ventilation rate measurements in several samplss of housing. This work led os to the conclueion that the main source of indoor radon is usually the soll and rock underlying buildings, and that it is the variability in the entry rate from this source that causes most of the hundred- or thousand-fold differences in radon concentration seen from house to house. Thus ventilation rate is not ordinarily the main consideration for indoor radon. We and others in the community are now heavily engaged in studies to understand in more detall how radon enters houses and how radon progeny behave after they are created from the radioactive decay of radon in indoor air. As described below, the behavior of the progeny depends heavily on theivinteraction either with airborne particles (e.g. from combustion sources) or with the bullding structure and its ventilation systems. (see FIgs. 3-4 and Refs. 9-15)

formaldehyde and other organics: Work on formaldehyde has demonstrated a clear dependence of the Indoor concentration on a building"s materials or contents; future work ought to include study of the dependence of formaldehyde emission rates on indoor c unditions: temperaturi, humidity, and ventilation rate. Our work on organics, in addition to demonstrating directly the pisesence of a large array of cumpunds in commercial buildings at levcls that far exceed concentrations outside the bulldings, has focussed on characterization of he emission spectrum from various building materials and on the correspondence between this information and the substances actually found to be present in injoor air. Further work required is the deternination of emission races in an environmental chamber that can provide realistic conditions, the development of more effective (e.g., simpler) monitoring approaches, and the establishment of a data base for developing a correspondence between concentrations observed in buildings and health effects among the sccupants. (See Tables 1, Fig. 5, and Refs. 16-19)

development and characterization of passive samplers: In support of our interest in elucidating the dependence of indoor concentrations on various factors, we have devoted significant effort to advancing the state of the art of passive samples, including testing of the performance of an $\mathrm{NO}_{2}$ sampler that was previously available, development and testing of a formaldehyde sampler that is now widely used, and -- currently - development of samplers for $C O$ and water vapor. The facility we have established is unique in its capabilities for characterizing performance of such integrating passive devices. It can therefore lend direct support to formulation of large-scale monitoring efforts that use such samplers. It can also be used for developing novel applications of these devices to the measurement of air velocity and ventilation iffectiveness, questions that are of substantial interest in characterizing the behavior of indoor air pollutants. (See Figs. 6-7 and Refs. 20-2!)

control techniques: Our largest effort in this area to date has been the characterization of the thermal performance and enviranmental effectiveness of sustems that provide ventilation, thereby removing pollutants, while incorporating air-to-air heat exchangers to recover heat that would ordinarily be lost with the ventilation a1r. Recent 


\section{HCHO Passive Sampler}

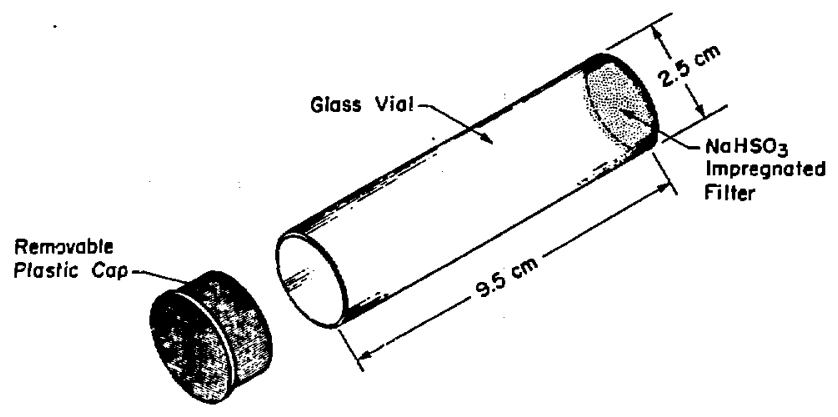

RESIDENTIAL INDOOR AIR HCHO CONCENTRATION

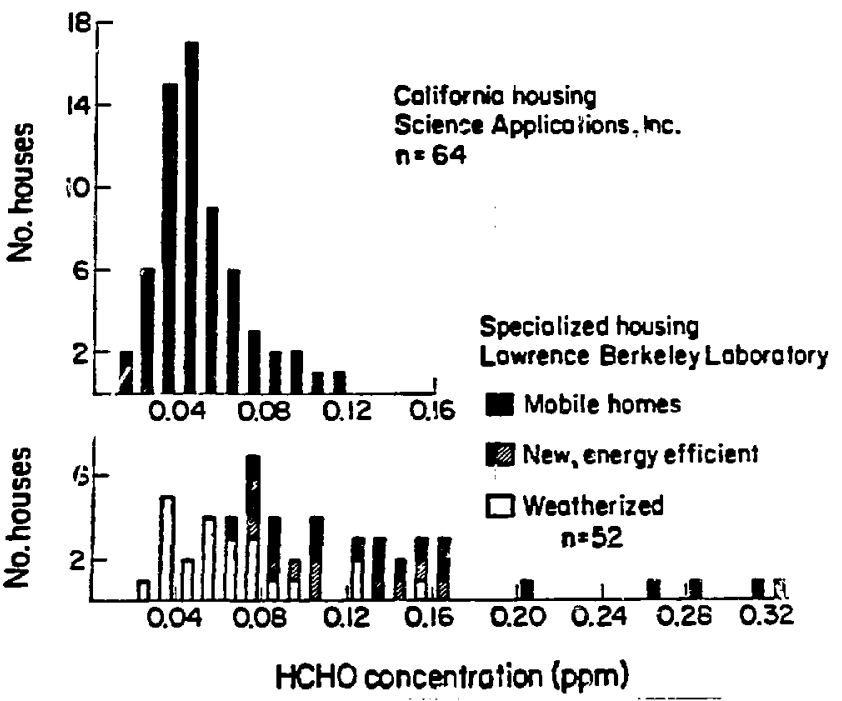

Figure 6 (top) Passive formaldehyde sampler designed at LBL. Formaldehyde diffuses Inco the glass tube after removal of the cap for a specified period of time. After recapplng, the filter is analyzed for HCHO in the laboratory using the chromotropic acid method.

Elgure 7 (bottom) Measurements of formaldehyde concentrations in conventioñal (lop data set) and speclalized (bottom data set) housing in callfornia. These data were collected using the HCHO passive sampler. 


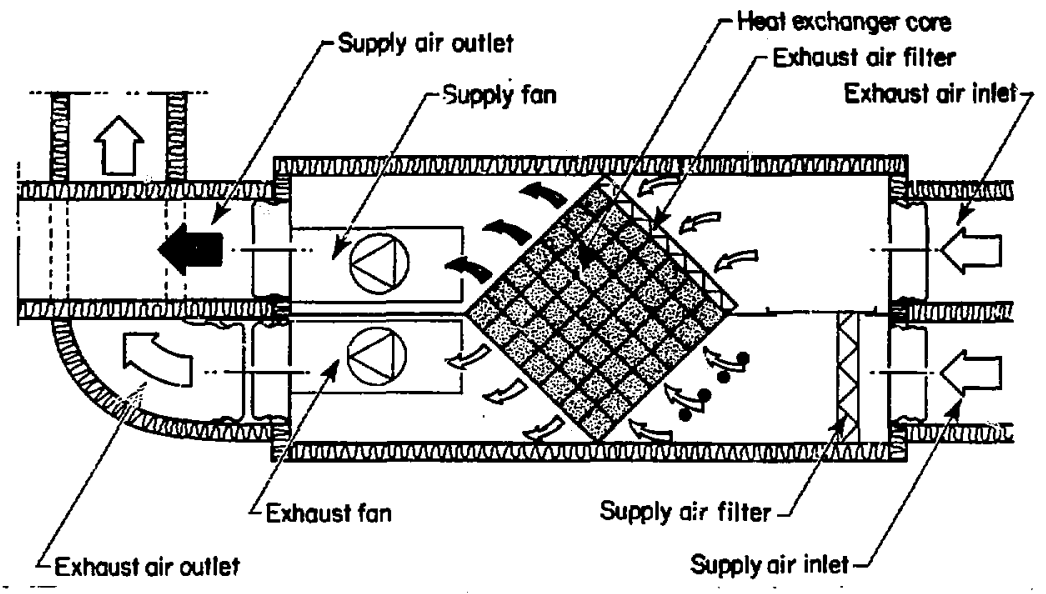

Average percent change of measured parameters in 9 Rochester, NY houses

Sensible heat exchangers (7 houses)

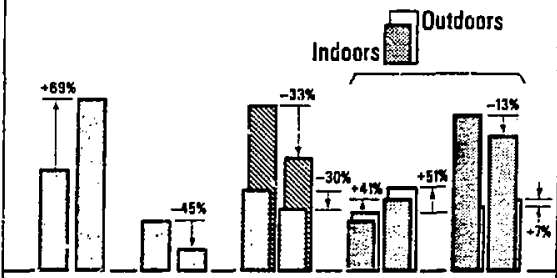

Sensible/latent heat exchangers (2 houses)

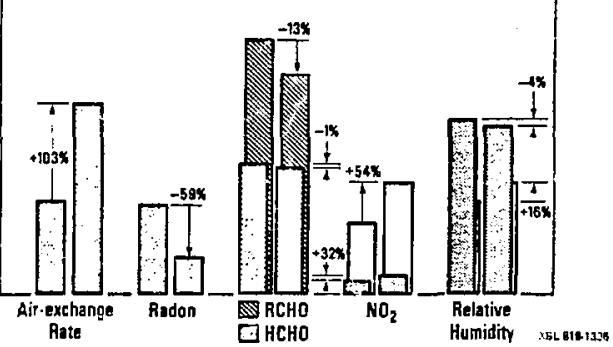

Hert oxchenger End locition $90 \mathrm{~cm}$ whove yoor
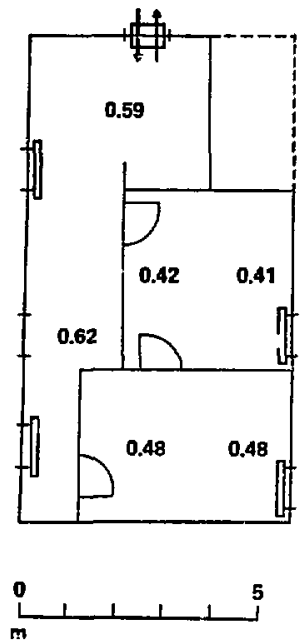

Figure 8 (top) Schematic of a mechanical air-to-air heat exchanger.

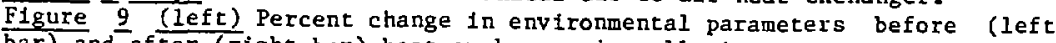
bar) and after (right bar) heat exchanger installation. Flgure 10 (right) Relative ventilation effectiveness at various locations within the test space. 
work includes the study of the effectiveness of this approach in providing ventilation throughout the space in single-family dwellings, study of ventilation effectiveness for other types of systems, and experiments on the use of air washing to remove formaldehyde from indoor air. Substantial work remains to be done, wot only on the topics just mentioned, but on other pollutant-specific control techniques, ranging from examining how different wall materials selectively remove chemically active airborne pollutants (such as No, or radon progeny) to the effectiveness of various active alr-cleaning and ventilation techniques. Examples are given below in the discussion of particulates. (See Figs. 8-10 and Refs. 22-26)

Some general conclusions can be derived from this broad range of work on indoor pollutants :

- perhaps most signiffcant from the point of view of energy conservation is that, although it is clear that a substantial reduction in ventflation rates (e.g., by the factor of 5 or so that is within technical reach) would have a strung adverse effect on indoor air quality -- at least in the absence of corresponding control measures - the main cause of widely different indoor concentrations in the ordinary housing stock is the strength of pollutant sourses rather than the variabjlity in ventilation rates. This is not to say that venillation rate is not important, but rather that assurance of good indoor air quality requires attention to both sources and ventilation rates, as well as other factors that affect indoor concentrations.

- monitoring programs and exposure characterization have to take account of the various factors affecting indoor concentrations, and should ordinarily include components for acquiring information on source and ventilation characteristics.

-- strategies for controlling indoor pollutant levels, whether in the context of conservation programs or for the purpose of reducing excessive levels within the general housing stock, should take account of the dependence of the performance of various control techniques on source and ventilation characteristics; moreover, consideration of the dependence of concentrations on housing type or location, or on the presence of specific materials or appliances, can focus control efforts much more effectively than would otherwise be possible.

Perhaps the most general conclusion to be reached is the need for continued work investigating the dependence of indoor concentrations on varlous factors, work that should be carried out in close cooperation with efforts to monitor indoor cencentrations within the building stock, to understand the health effects of indoor pollutants, and to formulate strategies for their cuntrol.

Finally, it is worth mentloning that this summary of LBL work is not comprehensive, but indicates the main results of our efforts. I have referred to some of our group's publications, in particular the principal ones associated with the wark summarized above.. These efforts have been supported primarily by the Department of Energy's Office of Conservation and Renewable Energy, to a somewhat lesser degree by LOE's Offlce of Health and Environmental Research, in the office of Energy Research, and to a yet smaller -- although still substantial -- degree by the Bonneville Power Administration, the 
Environmental Protection Agency, and the Consumer Product Safety Commission. Continuation of research in the areas indicated above is dependent on the balance of funding in the future.

Part1eulates, Radon Daughters, and The1r Control

I will now turn to a review of the state of knowledge of indoor parilculate concentrations, both because this is appropriate to the structure of these hearings and because particulates represent a prime example of the need for the kInd of characterization effort that I emphasized above. Along this line, I will address the question of Interactions between particulates and radon daughters and the implications for control of either of these species. However, I will first touch briefly on the information now available on indoor particulates.

Knowledge of the sources, concentrations, and chemical composition of indoor airborne particulate matter is only fragmentary. Moreover, even mere than for other indoor pollutants, the suitability of comparisons with outdoor concentrations or standards is questionable since measurements are often acquired on a different basis and the outdoor (national) standards simply cite total suspended mass, taking no account of differences in size or composition. Moreover, as will probably become evident in the second day of hearings, there are corresponding difficulties in ascribing health effects to particulate exposures, whether outdoors or indoors.

St1ll, it is known that indoor concentrations of total particulates or respirable particulates (those with size in the range of a micron or less) of ten approach or exceed outdoor levels or the standards that are applied outdoors. The strongest source of particulate indoors is cigaretre smoking, to which almost the entire population is exposed either at home or elsewhere. Particulates also arise from any combustion appliance, from various types of materials Indoors, and - of course - from the alr that enters from the outdoors. Hiwever, the bullding shell can act as a signiflcant barrier to entry of particulates, and -- in any case -- it is typically the particulates that are generated indoors that are of more concern.

A modest amount of work has been performed in characterizing the chemical and physical form of particulate matter that is found indoors or that is emitted from various indoor sources. It is known, for example, that the particulates in indoor alr due to cigarette smoking contaln a large number of compounds, many known to be carcinogenic, and that these particulates - like most found 1ndoors -- are in the respirable size range. For the most part, combustion appliances generate a relatively small amount of particulates, but -- in some cases (e.g., wood stoves) - - their composition is such as to be of concern, and the presence of higher-than-average numbers of particles In the alr may any case have significant implications for other pollutants that are present. Sutstantial work remains to be done to characterize the amount, size, and composition of particulate matter in 1ndoor air. This will require substantial monicoring efforts in existing buildings and, perhaps even more important, fundamental studies of the behavior of particles indoors. 
We are unable to say much about particulate behavior, even though -- as for the outdoor atmosphere - it lies at the root of some of the main questions. For example, we know little in general about the interaction of particulate and gaseous species indoors. And although we do not expect the specific smog reactions that are so important outdoors to occur substantially indoors, there is every reason to suspect that gas-particle reactions can be important. This could include reactions between particulates and gaseous combustion pioducts, condensation of organic compounds on particulates, and interactions between particles and radon daughters. The last type of interaction is known to have a profound effect on radon daughter behavior indoors and on the health effects associated with exposure to radon daughters. I will now turn briefly to these questions.

Unlike radon itself, a gas that does not interact chemically, the decay products (or progeny) are chemically accive and can attach to airborne particles or to walls, can be collected efficiently in air cleaning devices, and can also deposit in the lung - either directy or along with particles to which they are attached - when they are inhaled. $T$ point out two key factors in ccnsidering the importance of attachment of the progeny to particies: first, in the absence of. particles, the progeny tend to stick to walls at greater rates, so that they cannot be breathed, but, secondly, a greater portion of the particles remaining in the air under such conditions remain unattached. The progeny that are unattached are thought to have a greater probability of causing significant radiation exposures (and hence added risk of lung cancer). Thus it is not clear whether low particle concentrations are an advantage or a disadvantage. In any case, a good deal of study is now being given to the determination of progeny attachrent rates to particles in various size ranges, since this will in any case affect strategles for controlling exposures to radun progeny.

I can point specifically to work being performed at LBL's radon research house, a facility that was established to study the behavior of radon progeny (and which has also been used for a number of other studies). A key element in the particle/radon-progeny studies has been characterization of mechanisms affecting progeny concentrations, and these have included attachment to particles, attachment to walls, and removal by air-cleaning systems or devices. Study of air-cleaning has also been an interest of our group from the simple verspective of particulate control. An example of work that relates to both of these questions has been a recent study of the performance of a variety of stand-alone air-cleaning devices, as distinguished from those incorporated into a whole-building heating or cooling system. In these studies, we determined the effectiveness of these devices for removing particles in varfous size ranges and for removing individual radon progeny, using the unusual capabilities of the radon research house. Not surprisingly, the effectiveness of the several devices differed substantially. (See Figs. 11-12 and Refs. 27-28)

This points out a major gap in understanding the effectiveness of air-cleaning devices for removing particulates. If their effectiveness has been measured at all, this is usually limited to 

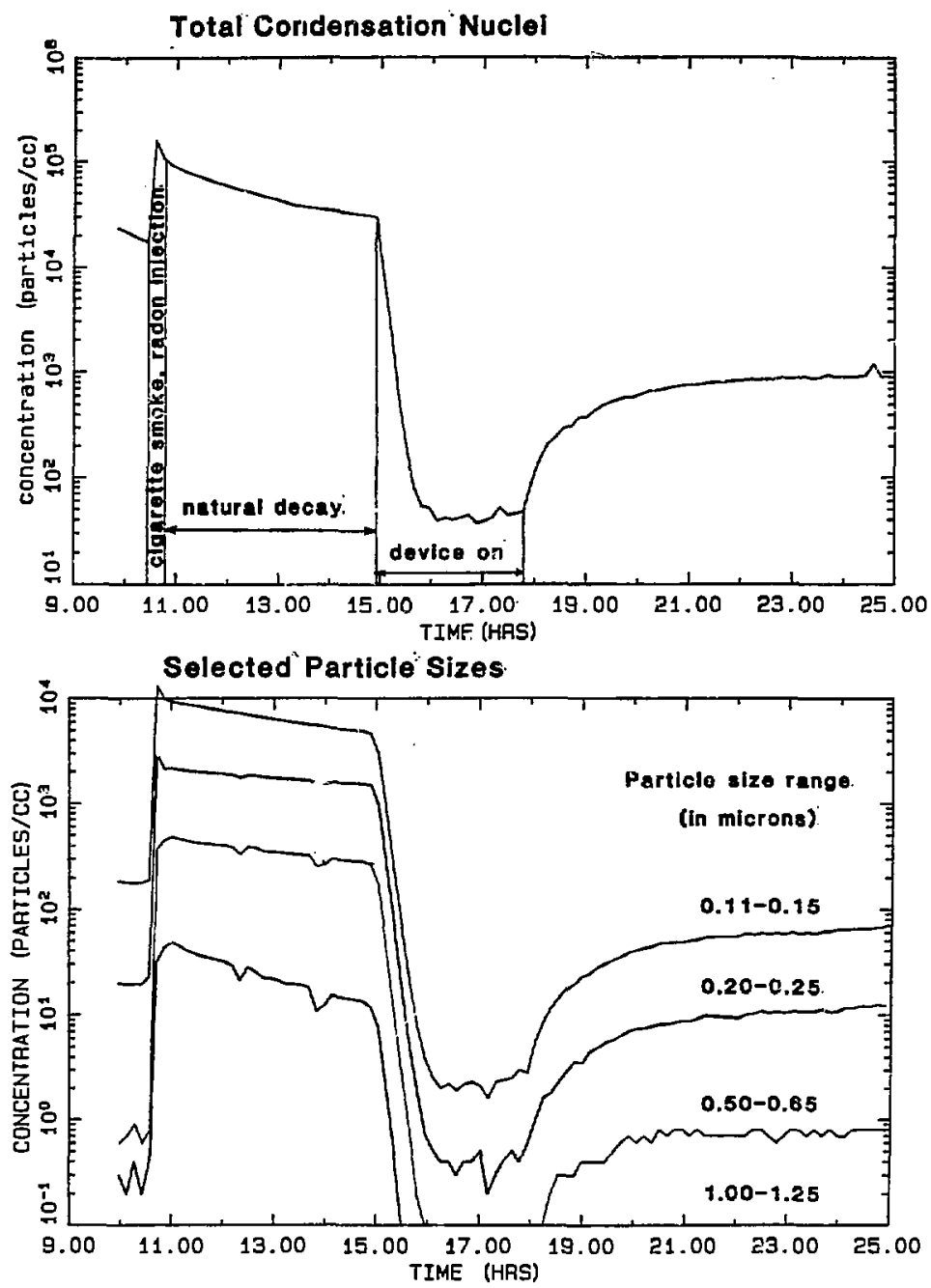

Fisure 11 (top) Concentration profile of total particulates before, durtng and after operation of an air cleaning device containing a High Efficiency Particulate Alr filter. These measurements are designed to evaluate the effectiveness of various air cleaning devices for control of particulate and radon progeny concentrations.

Figure 12 (bottom) Same as Figure 11, showing concentration profiles of particles in selected size ranges. 
measurement in terms of total particulate mass, occasionally in terms of particle size, and virtually never in terms of the effect on particular chemical or physical spectes, e.8., organics or radon progeny. In general the overall effect of air-cleaning devices on the pollutants present in indoor air is simply not known. The effectiveness of such devices and in fact of any control technique will only be understood in the context of future research on the behavior of airborne pollutants indoors, giving due welght to the interactions that pollutants have with each other and with the building and its contents.

Indoor Alr Quality Research Needs and Cooperation Requirements

Most will agree that a substantial amount of research remains to be done in the area of indọor air quality, and I have emphastzed requirements for characterization of indoor poilutant behavior, which -- in turn -- is closely tied to understanding the implications of energy conservation measures for indoor alr quality. A summary of research needs in the areas I have treated will make clear the strong connection between this work and that required for monitoring, health studies, and formulation of control strategles.

For each of the pollutant classes I have discussed -- combustion products, radon and its progeny, and formaldehyde and other organics - and also for those I haven't treated - spores, viruses, lead, asbestos, etc. - further nttention has to be given to the origin of the various specles, to their interactions once they are in the air, and to thetr removal by ventllation and other mechanisms. The balance of work rewaining in these areas depends on the pollutant class:

- combustion emissions have been adequately characterized for some appliances, but much remains to be done on the effects of combustion modification, on the effectiveness of local versus general ventilation, and on the interaction of these emissions with other species and with the building structure and ail-cleaning techniques other than ventilation.

- radon and its progeny are krown to have a wide range of concentrations indoors, dependent mainly on entry rates, and future work ought to emphasize the petential for systematic identification of houses with high source strengths, the mechanisms for radon entry into housts, and the behavior of radon progeny indoors.

- Formaldehyde and other organics are known to arise from a large variety of bullding materlals, as well as from combustion processes, and the areas requiring study are the dependence of emission rates on temperatures, humidity, and ventilacion rates, the potertial for reducing these emission rates, and - in the case of organics -- more effective monitoring techniques.

Elucldating these questlons in the laboratory or in small numbers of homes often requires the development of sophisticated techniques for performing intensive and detailed measurements. At the other extreme, studying the dependence of indoor concentraitions in the building stock at large requires simple, inexpensive monitors. The capabilities for development and characterlzation of such devices is an important element in programs for monltoring 1ndoor air quality on a large scale, as discussed below. 
Finally, the study of Indoor pollutant behavior in general, and of the effectiveness of various techniques for controlling pollutant concentrations, constitutes the basis for formulating control strategles: techniques that require further study include modification of sources, emission reduction by sealants er local ventilation, and removal from indoor air by general ventilation, air filtration, or use of adsorbent materials.

Such work as I have described, which is emphasized by our group because of Its connection with bullding design and operation, and hence energy conservation measures, is clearly connected with interests of agencies other than the Department of Energy (DOE): the Consumer Product Safety Commission (CPSC) is interested in effects of appliances, materials, and other preducts used Indoors; the Environmental Protection Agency (EPA) has a definite Intarest in exposure to alr follutants, many of which are found indoors; and the National Institutes of Health (NIH) has an interest in the health effects cf such exposures. Thus it would not be difficult to associate the EPA with monitoring, the NIH with health studies and DOE and CPSC with characterization, employing the terms used above. Yet these areas cannot be separated entirely, although the main interests of specific agencles or selentific disciplines can be defined generally. An example of the need for collaborative effort among the scientific community, and of joint support frcir the agencies, is the prospect of a large-scale program to characterize indoor pollutant concentrations, buililing-related factors, and occupant health in a sample of many thousands of houses selected across the United States.

A summacy of what such a program might entail is given in an attachment to this statement. The objective would be to select a large "full sample" of housing in which a number of key pollutants are measured, using integrating passlve samplers of the $k$ ind discussed abuve, in which building characteristics related to sources and ventilation rates are examined, and for which information on acute and chronic health effects of the occupants is acquired. In a subsample, more intensive measurements would be performed. Given our present knowledge of indoor alr quality and the present state of the art in monitoring, the objective of this program would be to make a glant step forward in understanding the distribution of pollutant exposures among the general population, the association of these exposures with building-related factors, and the health effects that may be assoclated with these exposures. It would obviously require a sicons collaborative effort, drawing on the full resources of the scientifir: communtty, and bringing physical and health scientists together to a degree that has not yet occurred in this area. The support and development effort required to move forward with this program could reasonatly be carrled forward with funding from nomal healthy agency budgets. The main monitoring phase would probably require a specific appropriation.

Effective progress on this and other major elements in a vigorous program on indoor air guality has as a principal requirement substantial support from the federal agencles, as indicated in the second document that I have attached. The consensus of all studies of needs 
for Indoor air quality research is that the main support for research per se can only be provided as a federal responsibility, and that this should be complemented in a very practical way by industry efforts and by state and local activities. But, presuming such federal support, coordination of the effort, for example in a national indoor air quality survey, is obviously necessary. This must entall cooperation at two levels: clearly the agencles themselves nead a mechanism for identifying their principal responsibilities and for communication of research results, and secondly the research community itseli could improve its own awareness and selection of the wide range of research projects required, while at the same time more effectively providing advice to the supporting agencies. The first requirement can be satisfied by resurrection of an interagency committee on indoor air quality. Constitution of a national scientific cummittee on indoor air quality would help the research community keep track of research progress and priorfties, while advising the agencies effectively.

How to create effective cooperative mechanisus is a topic on which I will not say more. In fact, I would offer the caution that coordinating mechanisms be defined in a way that still manages to encourage inftiative and creativity at the ievel of botis the federal agencles and research groups. Progress in understanding indoor air quality is like any public issue that has a major scientific component. Resources must be devoted to basic scientific work, to large-scale information gathering, and to technical and policy decisions on appropriate strategles for dealing with the basic issue, which in this case is the public health consequevies of Indoor air pollutants. The best progress in each area can be had by charting a course of research that effectively addresses the main questions, expecting active cooperation among the particlpants and anticipating that there will be some modest overlap. Rather than being waste, such cross-fertilization can give rise to new points of view and novel approaches that will ultimately speed us toward our objectives. These are characterization of the extent and health implications of indoor pollutant exposures, as well as the factors affecting indoor pollutant concentrations, and formulation of strategies for assuring good indoor alr quality. 


\section{REFERENCES}

1. Hollowell, C.D., and G.W. Traynor, "Combustion-Generated Indoor Alr Pollution," Proceeding of the 13th International Colloquium on Polluted Atomspheres; Par1s, France (April, 1978).

2. Berk, J.V., C.D. Hollowell, C. Ifn and J.H. Fepper, "Deslgn of a Mobile Laboratory for Ventilation Studies and Indoor Alr Pollution Monitoring," Lawrence Berkeley Laboratory report number LBL-7817 Rev, 1978.

3. Berk, J.V., C.D. Hollowell, J.H. Pepper and R.A. Young, "The Impact of Reduced Ventilation on Indoor Air Quality in Residential Bulldings," Atr Pollution Control Association 73rd Annual Meeting, Paper 80-61.1, Montreal, Cananda (June, 1980).

4. Girman, J.R., M.C. Apte, G.W. Traynor, J.R. Allen, and C.D. Hollowell, "Pollutant Enission Rates fron Indoo: Combustion Appliances and Sidestream Cigarette Smoke," Environment International, $8,213-221$ (1982).

5. Traynor, G.W., M.G. Apte, J.F. Dillworth, C.D. Hollowell, and E.M. Sterling "The Effects of Ventilation on Resdentla: Air Pollution Due to Emissions from a Gas-Fired Range," Environment International, 8, 447-452 (1982).

6. Traynor, G.W., D.W. Anthon, and C.D. Hollowell, "Technique for Determining Pollutant Emissions from a Gas-Fired Range," Atmos. Environ. 16, 12:2979-2988, 1982.

7. Traynor, G.W. J.R. Allen, M.G. Apte, J.R. Girman, and C.D. Hollowell, "Pollutant Enissioms from Portable Kerosene-flred Space Heaters;" Environ. Sc1. \& Technol. (1n press).

8. Traynor, G.W., J.R. Girman, J.R. Allen, M.G. Apte, A.R. Carruthers, J.F. D1llworth, anc V.M. Martin, "Indoor Air Follution Due to Emission from Unvented Gas-fired Space Heaters," Paper 83-9.6 presented at the Air Pollution Control Assoc. 76th Annual Meeting June 20-24, 1983.

9. Nero, A.V., "Indoor Radiation Exposures from Radon and 1 :s Daughters: A V1ew of the Issue," Health Physics 45, 277-288, 1983.

10. Nazaroff, W.W., M.L. Boegel, C.D. Hollowell and C.D. Roseme, "The Use of Mechanical Ventilation with Heat Recovery for Controlling Radon and Radon Daughter Concentrations in Houses," Atmospher1c Environment 15, 263-270 (1981). 
11. Ingersoll, J.C., "A Survey of Radionuclide Contents and Radon Emanation Rates in Building Materials Used in the United States," Health Physics 45 , in press.

12. Jarzaroff, W.W., M.L. Boegel and A.V. Nero, "Measuring Radon Source Magnitude in Residential Buildings," Radon and Radon Progeny Measurement, U.S. Environmental Procection Agency, Montgomery, Alabama, August 27-28, 1981.

13. Nararoff, W.W., F.J. Offermann and A.W. Robb, "Automated System for Measuring Alr-Exchange Rate and Radon Concentration in Houses," Health Phystcs 45 , in press.

14. Nero, A.V., "Airborne Radionuclides and Radiation in Buildings: A Review," Health Physics 45, in press (Based on chapter prepared for NAS).

15. Nero, A.V., M.L. Boegel, C.D. Hollowell, J.G. Ingersoll, and W.W. Nazaroff, "Radon Concentrations and Infiltration Rates Measured in Conventional and Energy-Efficient Houses," Health Physics 45, in press.

16. Mksch, R.R., D.W. Anthon, L.Z. Fannting, K. Revzan, J. Glanville and C.D. Hollowell, "A Modified Pararcsaniline Hethod for Determination of Formaldehyde in Atr," Analytical Chemistry 53, 2118-2123, 1981 .

17. Gelsling, K.L., R.R. Miksch, and S.R. Rappaport, "The Generation of Dry Formaldehyde at PPB to PPM Levels by the Vapor-Phase Depolymerization of Trioxane," Analytical Chemistry, 54, 140 (1982).

18. Offermann, F.J., J.R. Girman, and C.D. Hollowell, "Midway House-Tightening Project: A Study of Indoor Air Quality," Lawrence Berkeley Laboratory report number LBL-12777, 1981.

19. Muksh, R.R., C.D. Hollowell, and H. Schmidr, "Trace Organic Contaminants in Office Spaces," Environment International, 8, 129-137 (1982).

20. Gelsilng, K.L., M.K. Tashima, J.R. Girman, R.R. Miksch, and S.M. Rappaport, "A New Passive Monitor for Determining Formaldehyde in Ambient Air," Environment International, 153-158 (1982).

21. Hodgison, A.T., K.L., Gelsling, B. Remijn, and J.R. Girman, "Validation of a Passive Sampler for Determining Formaldehyde in Residential Air," Lawrence Berkeley Laboratory report number LBL-14625, 1982. 
22. Fisk, W.J., G.D. Roseme, and C.D. Hollowe11, "Performance of Residential Alr-to-Alr Heat Exchangers: Tést Methods and Results," Lawrence Berkeley Laboratory report number LBL-11793, 1980.

23. Fisk, H.J., K.M. Archer, P. Boonchanta, and C.D. Hollowell, "Performance Measurements for Residential Air-to-Air Heat Exchangers," Presented at the Intln symposium on Indnor Air Quality, Health and Energy Conservation, Amherst, Mass., Oct. 13-16, 1981, Lawrence Berkeley Laboratory report number LBL12559,1981 .

24. Offermann, F.J., C.D. Hollowell, W.W. Nazaroff, G.D. Roseme, and J.E. Rizzuto, "Low Infiltration Housing In Rochester, New York: A Study of Alr-Exchange Rates and Indoor Air Quality," Environment International, 8 , 435-445 (1982).

25. Fisk, W.J. and I. Turiel, "Residential Air-to-Air teat Exchangers: Performance, Energy Savings, and Economics," To be published in Energy and Buildings.

26. Offermann, F.J., H.J. Fisk, D.T. Grimsrud, B. Pedersen, and K.L. Revizan, "Ventilation. Effictencles of Wall-or-Window Mounted Residential Alr-to-Air Heat Exchangers," To be presented at the 1983 ASHRAE Annual Meeting, June 26-30 Washington, D.C. and published in ASHRAE Trans. 89 II (1983).

27. Nazaroff, W.W., K.L. Reyzan and A.W. Robb, "Instrumentation for a Radon Research House," Extended summary of paper presented at the Intl. Symposium on Indoor Air Quality, Health and Energy Conservation, Amherst, Mass., Oct. 13-16, 1981, Lawrence Berkeley Laboratory report number LBL-12564, 1981.

28. Nazaroff, W.W., "Radon Daughter Carousel: An Automated Instrument $2 q^{2}$ Measuring Indoor Concentration of ${ }^{218}$ Po,

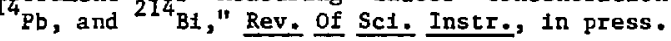




\section{A NATIONAL SURVEY OF INDOOR AIR QUALITY}

Our basic understanding of indoor air pollutant concentrations and how they may be measured conveniently has now advanced sufficiently to warrant the beginning of efforts to conduct a national survey of indoor air quality, carried out on an interagency, interlaboratory basis. The objectives of this survey would be to determine average concentrations of key pollutants to which the U.S. population is exposed, to delineate the range of concentrations and their dependence on building features, geographic location, and use patterns, and to use this dis:andence on concentration to examine the health effects of key indoor pollutants.

The differing objectives correspond roughiy to the differing interests of vartous Federal agencies. For example, it is the dependence of indonr pollutant concentrations on building characteristics and ventilation (rates and patterns), both connecied to anergy use, that gives rise to Department of Energy (DOE) Interest in this program. Environmental Protection Agency (EFA) interest arjses directly from the question of indoor human exposures and their contribution to total exposures. Similarly, the National Institutes of Health (NIH) has an interest in efforts intended to delineate the corinection between health effects and indoor afrborne pollutants that may be causetive igents.

Accomplishing these objectives will require substantial efforts on the part of the entire Indoor afr quality research community and the support of the several Federal agencies with an interest in indoor air quality, as well as the cooperation of private-sector energy research institutes and analytical laboratories. Members of the research community have been holding discussions among themselves and wit:. Federal agenites and other entities on how such a national survey might be undertaken. This survey is generally acknowledged to be a principal element in national efforts to characterize indoor air quality.

Technical Approach:

The overall structure and majcr elements of such a program are yet to be determined. The major thrust of the program will be the monitoring if key indicator pollutants, using simple techniques, 1 I many thousands of homes across the country, at the same time acquiring information-based on questionnaires-on the homes being monitored and on the health of the occupants. The program would provide basic infcrmation in three areef: pollutant concentrations, the various factors that affect them, and che health effects caused by them.

Considering the monitoring techniques available or soon to be available, the pollutants measured will presumably include nttrogen dioxide, radon 222, formaidehyde, and possibly carbon monoxide, but others may also be included in the full survey sample. In additfon, more intensive investigations will be undertaken in a subset of the full sample, with several purposes: first, to obtain at least a modest amount cf information on a more complete pollutant spectrum (Including, for example, particulates and volatile organics) than is pracical in the rull sample; second, to help establist a basis for interpreting the results from the full sample, 1.e., by using the subset to study the dependence of concentrations on time, environmental conditions, use patterns, and detafled bullding 
and ventilation characteristics; and, third, to obtain more detajled heal th-related information, as appropriate.

Major organizational questions include scientific direction of the effort, mechanisms for interagency support for the study, and the involvement of utilities and private-sector laboratorfes in actually performing the full sample survey. The indoor air quality research community is highly diverse, and ultimately many parts of it would be involved in this program. For the time being, members of a nimber of U.S. research groups are engaged in discussions about the form, funding, and implementation of such a survey.

Key objectives ror the next two years appear to be:

1. design and planning of the survey and performance of supporting development work that may be required; and

2. Impiementation of a pilot study using the techniques that are tentatively selected for the maiz survey.

Diring the second year, in parallel with a pilot survey, substantial effort will be devoted to selection of the main study sample, final design of the survey, Including the protocols for both the full sample and the intensive subsample(s), and creation of the cooperative infrastructure for performing the measurements. Any development required will be performed in parallel sith these efforts. On completion of this preparatory work, the main survey itself can actually be conducted ind the results analyzed. The full survey sample will have three major elements :

1. monitoring of the key poll ants of interest, such as those indicated above, relying primartly on simple passive samplers, many of which as: already available;

2. characterlzation of the buildings being monitored, including visual inspection of key source and ventilation-related characteristics, and information on use pat erns, all intended to Investigate the correspondence between pollutant concentrations and factors such as sources, ventilation rates, other: removal mechanisms, and occupant behavior; and

3. survey of the health of the occupants, including both acute and chronic health information relying on epidemiological survey instruments of proven design; thought is now being given to cluster sample approaches that would focus efforts in a number of geographic areas, with stratification of the sample in each cluscer based on building and population characteristics. However, to capture the full range of pollutant dependencles, the full sample may neeit a component that is dispersed beyond a small number of clusters.

These three elements can be related directly to the interests of the Federal agencies with principle interests, although ultimately all of the components are interrelated. The intensive subsample studies would be designed to investigate each of these elements in more detail, as 
necessary, to maximize the breadtl and reliability of results from the progran.

\section{Program Implementation:}

This overall effort will take 4 to 5 years, with a total funding of $\$ 10$ to 15 milition over this period. Annual funding of about one-tenth this amount ( $1 . e ., \$ 1-1.5$ million or so a year) can reasonably be expected to be taken out of ordinary agency funding for indoor air quality, provided the agencies have vigorous efforts in this area. However, about half the total effort will be devoted to procurement for, and conduct of, the maln study $1 t s e l f$; requiring a specific allocation of funds.

The base funding indicated above from the varlous agencies will support the initial objectives indicated above (design and planning of the survey, plus conduct of a pilot study) and will provide continued technical support of the main survey effort from the princignl scientific groups. Procurement for the main survey will begin during the second year, and the main monitoring effort will be undertaken during the third year, with completion by the fourth. Analysis and interpretation of the data will be performed periodically as results flow in, with completion of analysis during the fourth (and fifth) year.

Substantial care has to be taken in the creation of an effective intarlaboratory approach to accomplishing this key element of a vigorous program of indoor air quality research. A notable aspect of the program will be the active collaboration of different scientific communities to accomplish the characterization, monttoring, and healtin-related objectives. The work will undoubtedly require the guidance of a national scientific advisory board, as well as the active assistance of the various agencies, presumably coordinated through an interagency committee. The next step is to define moxe fully a conceptual design for the program as a whole, paying specific attention to: the pollutants to be monitored, instrumentation selection, statistical design, selection of full and intensive samples, claracterization of building-related factors, acquisition of health information, etc. Once this is done, the various scientiflc groups can begin explicit effort to carrying out the program objectives. 
FEDERAL RESEARCH NEEDS ON

INDOOR AIR QUALITY AND ENERGY CONSERVAIION

Introduct1on

A major part of human exposure to alr. pollution occurs indoors to the general population in their own houses and offices. Exposures of comparable importa-ce occur due to outdoor pollution and to occupational exposure from spectfic work-related emissions. In the United States, thousands of deaths, and a much larger incldence of sickness or acute distress, occur annually due to outdoor and occupational exposures. This has been the maln reason for the assignment of substantial and explicit responsibilities for controlling these exposures to the Environmental Protection Agency and to the Occupational Safety and Health Administration. The amount of illness and death arising from indoor exposures appears to have a similar scale. This has prompted a number of agencles to begin research programs over the last decade or so with the purpose of either characterizing or understanding how to control Indoor air pollution in respects that are consistent with the missions of each agency. In spite of the importance of this question, the total federal allotment to research on indoor afr pollution is only a few million dollars per year, a small fraction of the funds devoted to programs on outdoor or occupational exposures. This commitment is extremely small considering the thousands of deaths per year (and larger Incldence of 1llness) that can be attributed to exposure to indoor air pollutants. Considering the complexity and importance of the findoor air pollution question and considering the potentially adverse impact on indoor exposures of new products and building designs (especially those incended to save energy), research efforts in this area ought to be increased significantly. Explicit acknowledgement of the special roles of several agencles in this area would also be helpful.

Considering the significance of indoor exposures, substantial concern arises from the potentlal effects of energy conservation measures on alr quality in the indoor environment. One of the most popular and cost-effective means of conserving energy is weatherization-the reduction of outdoor air infiltration--a measure that can result in increased concentrations of indoor-generated pollutants. In larger buildings ventilation rates are reduced to save energy with similar effects on Indoor alr quality. Thus, elevated indoor alr pollutant concentrations, which in some instances are already high enough to be a problem, may result from the implementation of certain energy conservation measures. Unless specific controls are slmultaneously applied, or intervening factors occur, elther the pace of bullding energy conservation prograus will be constralned or indoor air quality will suffer. Coplng with current levels of indoor pollutants, which now vary over thousand-fold ranges within he housing stock, and with the potential effects of energy-conser :ion measures, requires substantial attention to indoor pollutant behavior. This requires characterization of: 1) indoor sources, and the factors affecting emission or entry rate, 2) the effect of ventilation rates and patterns, including questions of local versus general ventilation and of venctlarion effecriveness, and 3) removal due to other mechanisms, such as interactions between pollutants and accachment to walls or HVAC system components. In the context of such work, 
we can understand the dependence of indoor concentrations on buildingrelated factors, including energy-conservation measures and techniques to control indoor pollutant levels. This understanding enables us to proceed with energy conservation programs while providing for good indoor ais quality.

Indoor pollutants can arise in different ways, and the origin of a particular pollutant affects the applicability of particular control strategies.

- Pollutants enter from outdoors. All pollutants found in the outdoor environment (e.g., $\mathrm{NO}_{x}, \mathrm{SO}_{x}, \mathrm{CO}, \mathrm{TSP}$, microbial spores, dust, pollen, etc.) can infiltrate indoors. In addition to outdoor air, soil gases (e.g., radon) may find their way directly into bulldings in significant quantities.

- Pollutants are generated by indoor activities. Domestic sources include routine cooking, cleanfing, smoking, hobbies, use of sprays, and emissions from the human body. Some heating appliances, such as unvented kerosene or gas space heaters, can emit very large amounts of pollutaats into the indoor environment.

- Pollutants can be emitted from building construction materials. Building materlals, Including concrete, wood products, paint, plastics, and insulation material may emit a variety of pollutants, including radon, asbestos, formaldehyde, and other organics.

As an indication of the last question, the status and general applicability of control via ventilation. air cleaning, source removal/exclusion, and source substitution are summarized in Table 1 . An additional method, education of the inhabitants, does not involve a system, as such, yet may well be an effective approach in controlling indoor air quality. These various control methods are not always independent. Finally, any Indoor air quality control strategy should satisfy health, safety, comfort, and energy conservation objectives while minimizing costs and changes in the way of life.

Work at the Department of Energy, which has the most apparent responsibility for research or energy conservation and indoor air qual1ty, has emphasized the effect of bullding design, Including energyrelated features, on the sources, concentrations, behavior, and control of indoor pollutants. As indicated below, the primary roles of the various agencies appear to differ from one another, and cooperation is required to avoid gaps or an undue amount of overlap in the areas being Investigated. In addition, industry has a substantial role to play in this area, focusing largely on their particular interests. Historically, federally-funded research has led industry efforts on indoor air quality. This is not surprising since-unlike those of industry-federal efforts have an explicit interest in detailid characterization and exposure monttoring, appiled in a consistent manner to the various aspects of incioor alr pollution. Industry has a clear role in evaluating its own product in a manner that is consistent with the developing picture on indoor air quality. 
Table 1. Indoor Air Quality Control Techniques.

Control Method

Comment

Forced Ventilation

Natural Ventilation

Infiltration

Local Ventilation and Heat Exchangers

Continuous Air Cleaning

Source Exclusion (entry prevention) Source Removal

Source Substitution
Widely used in industrial, institutional, commercial, and transportation environments. May require substantial energy for heating and cooling, or may improve energy efficiency, depending upon control system.

Efficiency as a control strategy is not well documented, but is expected to vary considerably. Noise considerations and high indoor pollution levels may limit effectiveness.

Ordinarily unintentional air leaks; energy waste is closely associated. Widely used in residential environments.

Efficient control strategies for both small and large buildings; research needed to quantify the efficiency of each strategy.

Pollutant dependent; effectiveness requires further documentation. Contaminant control devices are often large, expensive, noisy and require maintenance.

Can be very effective but requires extreme care in application to assure effectiveness; retrofit application may be very costly. Research needed to improve effectiveness.

Has not been widely used; feasible if the source is substituted with an equally functional alternative that does not generate indoor pollutants. 
The Need for a Government Role in Indoor Air Quality

Based largely on research that had been performed during the 1970 's, several international, national and industry or standard-setting organizations have recognized the importance of the ongoing work on indoor air quality to the extent that commitments were made to workshops, expert studies, and substantial research programs in this area. As examples, a World Health Organization working group report in 1979 sald:

"Since man spends up to $70 \%$ of his time (1ndoors) and air quality indoor was usually somewhere between that outdoors and in the occupational environment, further studies should be made on Indoor air quality, the factors that affect 1t, and tts role in the total adverse health effects" of air pollution. "Studies on the nature and races of emisstons of indoor contaminants, as well as the rates of their absorption and inactivation, are urgently needed..."

A National Academy of Sciences panel on indoor pollutants, reporting its findings in 1981 , recomended:

"Responstbility for sonducting a well-coordinated investigation of influence of bullding design and operational factors on the concentrations of pollutants in both residential and commercial facilitles should rest with federal government, assisted by the approprtate professional and sclentific oxganizations," with the inttial focus of investigation on:

- "the effects of reducing infiltration rates in existing buildings on concentrations of 1ndoor-generated alr pollutants;

- the effects of matertals of construction and furnishtings on indoor-pollutant content;

- the difference in a1r distribution, diffuston, mixing, etc., assoctated with the use of different climate-control systems;

- the effectiveness of air-cleaning systems in capturing pollutants in rectrculating afr."

The need for a greater federal role in research on and assurance of Indoor afr quality had also been called to the public attention in 1979 by an office of Technology Assessment report that said:

"It is now clear that indoor levels of several important air pollutants can be as high or higher than outdoor levels." The "low level of [Federal] effort is particularly difficult to understand."

A 1980 report to the Congress by the Comptroller General suggests a sason: 
"While Federal officlals agree that indoor air pollution poses a potentially serious health problem, they have been reluctant to invest resources to study it because they lack clear responsibility for addressing the problem." chas:

Einally, in respect to the role of Industry, ASkRAE said in 1982

\begin{abstract}
"While some incentives do exist in the private sector to conduct research and develop products related to indoor air quality government has an iuportant leadership role to sponsor research on indoor air quality, its human health consequences, and to advance the technology of contaminant control. No single professional society, manufacturing association, trade association, or branch of industry has the comprehensive interest, resources and competence in indoor air quality technology to insure that a well-funded systematic research program is conducted."
\end{abstract}

The message is clear: That indoor air pollution can have substantial health consequences, and that a more substantial and comprehensive research program of: 1) characterization (of sources, pollutant behavior, and control techniques-including the effect of various building design features), 2) monitoring, 3) health studies, and 4) control strategles must be unitertaken through a coordinated Federal effort. As ASHRAE says, "once [Federal] research has identified the needs for better solutions for improved health, the private sector will respond with improved, innovative, cost-effective solutions."

General R'sr onsibilities for Research on Indoor Alr Quality

Several Federal agencies have implicit or explicit responsibilities for research on indoor air quality. The significance of current levels of Indoor pollutants and the potential for increases due to measures that increase the efficiency of energy use in bulldings caused two agencies, the Department of Energy (DOE) and the Environmental protection Agency (EPA), to start significant research efforts on indoor air quality. (Both efforts were substantially decreased in size in 1981, exactly the opposite of the recommendations cited above.) Because of its explicit responsibility for research on energy conservation, and its specific role in research on building design and performance as related to energy, DOE has established a substantial and unique competence to examine the factors affecting Indoor pollutant concentrations. This focuses generally on sources, removal mechanisms and control techn'fues, and specifically on building design, ventilation rate (or 1ts reduction), and alr-cleaning systems. On the other hand, because of its general mandate for environmental protection and 1 ts specific responsibility for and competence in control of outdoor ("ambient") air pollution, the EPA has a substantial role to play in monttoring, risk assessment, and-mtogether with other agencies and industry associations-formulation of control strategies.

Most of the research needs cited above by the National Academy of Sciences and much of those cited by ASHRAE fall squarely into the area in which DOE has established unusual competence, 1.e., detalled research 
characteriaing 1ndoor pollutant behavior and 1 ts relation to energyefflclent bullding design. This competence includes not only laboratory investigations and fleld testing of the influence of ventilation on indoor air quality, but also the Implications of this work for design of large-scale field studies. This is true even though wide-scale general monttoring and assoclated regulatory responses (except to the extent this Involves building design parameters, per se) must be construed to be a folnt responsibility of the federal agenctes.

Focusing on DOE and EEA is not intended to minlze the responsibilities of other agencies, some of which, in particular the Consumer Product Safety Commission (CPSC) and the National Institute of Environmental Health Sclences (NIEHS), have made substantlal commltments to work on indoor alr quality. In effect, a spectrum of work is required in this area, and several agencles have explicit responsibilities for various aspects of follutant characterization, monltorlng, health studies, and formulation of control strategies. As indicated above, DOE is understood to have responsibility for examining how changes in bullding design (whether construction materlals, appliance, or ventilation techniques) that are intended to save energy also affect indoor air quality. DOE has therefore developed a unique capabilizy for examining how proposed or possible changes in bullding design affect indoor pollutant concentrations.

The other side of the fundamental research plcture is to investigate the health effects of indoor pollutants using epidemlological studies, clinical and animal studies, etc. While a varlety of such work relevant to Indoor exposures has been performed by several agencles (e.g., parts of DOE have historically investlgated health effects of radiation, modeled exposures due to combustion products, etc.), NIEHS in particular has undertaken substantial basic work on the health effects of indoor pollution as a general problem. The NLEHS work is oriented toward exposure measurement and health effects analysis at a more fundamental level than the monttoring and risk assessment generally associated with the EPA.

Another agency with responeibilities on indoor pollution is CPSC, which has a well-defined mandate to assure product safety. Consequently, matertals and appliances used in bulldings fall within their purview. In some cases, the CPSC's work related to indoor alr quality is an examination of products after they become avallable. (For this reason, industry has a clear incentive to consider indoor air quality as one basis for developing products that will pass such an examination.) In other 1nstances, CPSC could set performance requirements for new products. Sich CFSC activities have required significant research efforts, sometimes in-house and at other times in cooperation with other agencies (such as DOE) that have developed a sultable capability because of a common interest.

Other agencies also have interests in indoor air quality. The Department of Housing and Urban Development (HUD) has a a clear Interest in bulldings, an interest that now lies more in the direction of 1mplementation than toward research or assessment. The National Institute for Occupational Safety and Health (NIOSH) performs work on monitoring 
and control of exposures in occupational settings, a responsibility that can be construed to apply to commercial bulldings (including office environments) and, In any case, involves capabilities that are relevant (if not directly applicable) to monitoring of 1ndoor pollutants.

HUD's interest in implementation, CPSC's responsibility for product safety, EPA's mandate for environmental protection, and DOE's investigation of the effects of building design on indoor pollutant concentratlons is indicative of an ambiguity in responsibilities for indoor air quality research or--in this case-associated measures for public protection. Such ambiguity is by no mean peculiar to indoor air quality, but rather is characteristic of other questions of health or environmental protection. The agency interests just named all lie in the are of formulating strategies to assure adequate indoor air quality. They reflect genulne and appropriate, but differing, responsibilities of the varlous agencles. Anc, although EPA can (and ight to) be construed to have a general mandate to protect the public, the other entities named have differing areas of responsibility in respect to contributing to this protection which--with proper acceptance of these responsibilities and an appropriate level of coordination--can complement each other, rather than clash. Moreover, with these differing responsibilities are associated specific and substantial capabilities that, if fully util1zed, will contribute to a sounder and more timely program of research and protection of the public.

Research on Indoor Air Qualicy as it Relares Bullding Design and Energy Conservation

The central DOE responsibility has been to characterize the dependence of Indoor pollutant concentrations on bullding factors related to energy. To a greater or lesser degree, every pollutant has such dependence, if only through the ventilation rate and other factors related to the building heating or cooling systems. In addition, many of the follutant entry rates (for combustion products, radon, and organics) are affected directly by building features that are energy related-including again, ventilation conditions. The chiacterization of specific control techniques is an integral part of this work. Thus, central to effort on energy conservation and Indoor air quality should be characterization of the dependence of indoor levels on sources, ventilation rates, and other removal mechanisms (e.g., a filter in the HVAC system or an energy recovery system). Much of this can be accomplished by laboratory-based studies, supported by selected field efforts that determine in practical situarions the effect of energy-related features (e.g., Inflitration reduction). This intermediate level of investigatlon, 1.e., moderately-intensive laboratory studies and selected fleld efforts, is appropriate in direct connection with the programs on energy conservation in bulldings, such as those carrled out by DOE's office of Conservation and Renewable Energy. It contrasts with broad-scale monitoring programs (of elther DOE or EPA) or more intensive pollutant characterization studies, such as those carried out by the office of Health and Environmental Research. Assoclated with the efforts on conservation should be a modest effort devoted to: development of simple monitoring techniques (which are useful for the selected field studies Just mentioned), design of larger survey efforts (which would actuasly be 
performed together with others, e.g., as part of a national survey), and construction of a data base on house features and ventilation/ pollutant measurements that would constitute a functional model of the housing stock.

The work fust mentioned is necessarily supported by more fundamental characterization efforts, such as those funded by DOE/ER/OHER on radon behavior, by efforts to simulate indoor alr pollutant behavior by developing realistic physical models, and by examining the potential health effects of indoor pollutants as a partial basis for selecting acceptable bullding design features.

Note that several of these efforts, some of which have been supported by DOE until now, provide connections with other agencles, e.g., survey design and health risk assessment, both of which are related to NIEHS and EPA. The data base development, in addition, would directly involve industry organtzations.

The research needs set fortin below begin with projects that are explicitly related to energy conservacion in bulldings, then go on to basic characterization or health studies that support this work. Each of these areas has been the subject on continuing work at Lawrence Berkeley Laboratory or is a developing area in which new effort is approprlate.

\section{Building Energy Conservation and Indoor Air Qualicy}

Radon -laboratory and field measurements of radon sources and concentrations in conventional and energy-efficlent housing; identification, through geographic and geologic assessment, using aerial radiometric data, of regions in U.S. likely to have high radon concentrations; experimental study of radon entry into houses and of associated control techniques. (Work in this area is now supported by DOE/CE, and is complemented by support From DOE/ER/OBER on radon daughter behavior and from Bonneville Yower Admintstration [BPA] for FY83.)

Residential combustion appliances -characterize pollutants emitted by Indoor combustion processes, emphasizing study of concentration behavior as affected by ventilation conditions. Examines emissions from gas stoves/ovens, unvented gas-fired heaters, kerosene heaters, and wood stoves. (Work in this area is not now supported by DOE/CE; related efforts are being carried out for DOE/ER/OHEP, described below, and CPSC.)

Bullding matertal emissions -measure emissions from elected building materials and correlate with observed concentrations in home and office environments, examining dependence of emlssions/concentrations on ventilation rates, humidity, and temperature; Instrumentation development. (This work, to which renewed efforts have been devoted in the last year, does not have commltwents for support beyond this calendar year.)

Passive samplers --develop low-cost, portable, usually passive, samplers suttable for measuring indoor air quelity in research and energy-conservation programs; test and evaluate commercially-available 
monitors for sultabllity in indoor alr quality montoring; see also survey design, below. Development or characterization of monitors for $\mathrm{NO}_{2}$, formaldehyde, $\mathrm{CO}$, water vapor, etc. (DOE/CE's support of these efforts and of LBL's passive monttor test factilty is belng closed out.)

Control techniques --evaluate the energy performance, contaminant control capabilities, and economic performance of Indoor alr quality control techniques; assess feasibility of new techniques, emphasizing study of ventilation and active alr cleaning systems. Includes study of alr-to-air heat exchangers, filtration and washing systems, other heat recuperation devices. (This work has no commitment of funding from DOE/CE beyond FY83; heat exchanger work for DOE is being closed out. Short-term funding from DOE/EP, BPA, and EPA extends partially into FY84.)

Survey design --examine application of passive monitor packages in connection with energy-conservation programs or other large-scale survey programs; formulate approaches to statistically-valid selection of monttoring sites, interpretation of data, and handling of samplers; support for specific DOE programs, as well as large-scale programs in which DOE participates, such as a national survey of indoor afr quality. (This work has no current funding.)

Concentration of indoor pollutants data base --collect extsting data from measurements of indoor pollutant concentrations, ventilation rates, and housing characteristics in a user-oriented data base. (This effort is expected to be supported jointly by DOE, EPRI, and GRI.)

Undertaking work in the foregoing areas would require a higher level of funding than has been forthcoming in the last two years from DOE/CE.

Basic Characterization and Health Studies

Indoor alr pollution health effects --characterize Indoor air pollution and develop strategies to make assessments of health and exposure implications of indoor air pollution, especially as affected by energy-related features; has emphasized combustion products, with some assessment of radon risks; now emphasizing overall indoor air quality risk analysis, with specific interest in approaches to Improving information on health effects of combustion products, radon progeny, and organica. (Continued support from DOE/ER/OHER.)

Radon characterlzation -investigate through laboratory and field studies the behavior of radon and radon progeny; conduct studies in a research house of attachment of radon progeny to particles and deposition on indoor surfaces; related instrumentation development, numerical modeling, and studies of alr movement, all oriented toward influence of building design factors. (Continued support from DOE/ER/OHER.)

Indoor alr qualicy modeling -formulate elements of a multi-chamber residential indoor air quality model capable of realistically treating the varlous sources of indoor pollucants and their transformation, transport, and removal as affecsed by bullding design and ventilation/air cleaning systems. (This work has no current funding.) 
Indoor organic pollutants --identify airborne organic contaminants, characterize their sources, and understand the relationship between building practices (use of particular materials and design of ventilation system) and increased exposures; develop methodologies for identifying and quantify \pm ng trace organic contaminants in indoor air. (This work has no current funding; except for DOE/CE effort on butlding material emissions to end this calendar year.)

Indoor air quality control techniques --evaluate control techniques for maintalning acceptable indoor afr quality in bulldings with low ventilation rates or high source strengths; attention both to fundamental removal processes and to commerctally-avatlable devices; includes design and fabrication of an environmental chamber for contaminant-control studies. (This work has one-time funding from DOE/EP, BDA, and EPA.) 